\title{
Comparison of surface passivation of crystalline silicon by a-Si:H with and without atomic hydrogen treatment using hot-wire chemical vapor deposition
}

\author{
J.W.A. Schüttauf*, C.H.M. van der Werf, W.G.J.H.M. van Sark, J.K. Rath, R.E.I. Schropp \\ Utrecht University, Debye Institute for Nanomaterials Science, Nanophotonics - Physics of Devices, Princetonplein 5, 3584 CC Utrecht, The Netherlands
}

\section{A R T I C L E I N F O}

Available online 2 February 2011

\section{Keywords:}

Hot wire CVD

Surface pretreatment

Atomic hydrogen

Silicon heterojunction solar cells

\begin{abstract}
A B S T R A C T
We compared surface passivation of c-Si by a-Si:H with and without atomic hydrogen treatment prior to a-Si:H deposition. The atomic hydrogen is produced by hot-wire chemical vapor deposition (HWCVD). For this purpose, we deposited a-Si:H layers onto both sides of n-type FZ c-Si wafers and measured the minority carrier effective lifetime and implied $\mathrm{V}_{\mathrm{OC}}$ for different $\mathrm{H}$ treatment times ranging from $5 \mathrm{~s}$ to $30 \mathrm{~s}$ prior to a-Si:H deposition. We found that increasing hydrogen treatment times led to lower effective lifetimes and implied $\mathrm{V}_{\mathrm{OC}}$ values for the used conditions. The treatments have been performed in a new virgin chamber to exclude $\mathrm{Si}$ deposition from the chamber walls. Our results show that a short atomic hydrogen pretreatment is already detrimental for the passivation quality which might be due to the creation of defects in the c-Si. AFM measurements do not show any change in the surface roughness of the different samples.
\end{abstract}

(c) 2011 Elsevier B.V. All rights reserved.

\section{Introduction}

Amorphous and crystalline silicon based heterojunction solar cells form a potentially cheap alternative compared to conventional c-Si solar cells. In conventional c-Si based solar cells, the $\mathrm{p}-\mathrm{n}$ junction is usually formed by a thermal diffusion step for which temperatures of roughly $900{ }^{\circ} \mathrm{C}$ are needed. In case of a-Si:H/c-Si based heterojunction solar cells, however, temperatures below $200^{\circ} \mathrm{C}$ can be used, as the junction is formed by deposition of a thin doped a-Si:H layer. These lower temperatures (i) strongly decrease the thermal budget of the production process, (ii) decrease the thermal degradation of the c-Si wafers and (iii) enable the use of thinner wafers due to the reduction of thermal stress. Furthermore, the design of a-Si:H/c-Si heterojunction solar cells, in which the a-Si:H emitter is deposited on top of the c-Si wafer, enables the insertion of a surface passivating thin intrinsic layer consisting of a-Si: $\mathrm{H}$, which can increase the open circuit voltage of these structures to values exceeding $720 \mathrm{mV}$. Sanyo [1] has first introduced the concept of using such a thin intrinsic layer and inspired many other groups around the world to focus on this concept as well.

Prior to a-Si:H deposition, c-Si surfaces are usually dipped in hydrofluoric acid (HF) to remove native oxide and make them hydrophobic. Another pretreatment method that can be used additionally to an $\mathrm{HF}$ dip prior to a-Si:H deposition onto the c-Si wafer, is a so-called atomic hydrogen pretreatment. Such an additional treatment could help to improve the cleaning of the wafer surface, to remove residual oxide and fluorine and to passivate surface defects [2].

\footnotetext{
* Corresponding author.

E-mail address: J.A.Schuttauf@uu.nl (J.W.A. Schüttauf).
}

There are also several reasons why such a hydrogen pretreatment prior to a-Si:H deposition might have a detrimental effect on the passivation quality of such layers. First of all, the atomic hydrogen may selectively etch the c-Si wafer surface and therefore change its roughness [2]. Furthermore, it is reported [2], that such a treatment can create additional strain and defects in the $\mathrm{c}-\mathrm{Si}$ that have a detrimental effect on the surface passivation. Thirdly, an important possible mechanism that can influence the passivation quality is the deposition of a-Si:H onto the c-Si due to etching by atomic hydrogen of earlier deposited Si from the chamber walls. This process is often called 'chemical transfer'. Chemical transfer can be detrimental to the passivation quality but has also been reported [3] to have a positive effect on the passivation, especially if no intentional thin intrinsic layer is used between the c-Si wafers and the oppositely doped a-Si:H emitter.

In this work we report on such atomic hydrogen pretreatment in which hot-wire CVD dissociates the molecular hydrogen into atomic hydrogen. It can be expected that a pretreatment by atomic $\mathrm{H}$ generated by HWCVD can be effective in passivating the surface of a c-Si wafer, as there is no high-energy ion-bombardment that can potentially damage the c-Si surface. Several authors [2,4-7] have already reported on such a treatment by HWCVD and, interestingly, have found strongly varying results. NREL $[2,5]$ found no significant difference for short $(<10 \mathrm{~s})$ treatment times and a detrimental effect on the $\mathrm{V}_{\mathrm{OC}}$ in finished cells for longer treatment times. Muñoz et al. [6], for atomic treatment times of $1 \mathrm{~min}$, found a detrimental effect on surface passivation for p-type wafers coated on both sides with layer stacks consisting of intrinsic and n-type a-Si:H. Ohdaira et al. [7] report on an improvement of the passivation quality, as determined from $\mu$-PCD measurements on n-type $\mathrm{CZ}$ wafers passivated on both sides with $100 \mathrm{~nm}$ thick intrinsic a-Si:H. 
They also found a strong influence of the wire temperature during the atomic hydrogen treatment on the passivation quality, i.e., lower wire temperatures generally lead to higher effective lifetimes of the samples. The treatment time was also equal to $1 \mathrm{~min}$. Conrad et al. [3] found an increase in $\mathrm{V}_{\mathrm{OC}}$ on finished cells. In this case, the atomic hydrogen treatment was performed by PECVD on textured (111) c-Si wafers. The cells were made without a thin intrinsic layer between the wafer and $\mu c$ Si:H emitter of opposite doping to the wafer. The plasma treatment, however, which has been performed in the same chamber as the $\mu \mathrm{c}-\mathrm{Si}: \mathrm{H}$ emitter, might in fact have led to deposition of a thin a-Si:H film prior to the emitter due to chemical transfer from the chamber walls.

\section{Experimental details}

For our experiments we used $280 \mu \mathrm{m}$ thick double sided polished (DSP) n-type (100) FZ wafers $(2-5 \Omega \mathrm{cm})$. Prior to the atomic hydrogen treatment and a-Si:H deposition, the wafers were dipped in $\mathrm{HF}\left(1 \%\right.$ in $\left.\mathrm{H}_{2} \mathrm{O}\right)$ for $2 \mathrm{~min}$. Subsequently, atomic hydrogen treatments were performed in a new 'virgin' chamber, in which no $\mathrm{Si}$ containing depositions were ever performed prior to this experiment. This ensures that during the atomic hydrogen treatment, no $\mathrm{Si}$ can be deposited onto the c-Si by so-called 'chemical transfer' due to etching of previously deposited Si onto the chamber walls. A schematic overview of the reactor is given in Fig. 1. For the hot-wire atomic hydrogen treatment, two parallel Ta wires were used (diameter $0.3 \mathrm{~mm}$ ). The substrate holder is placed $20 \mathrm{~cm}$ above the two parallel wires. We used a wire current of $5.4 \mathrm{~A}$, which corresponds to a wire temperature of $1980{ }^{\circ} \mathrm{C}$ in vacuum. As a source gas, we used $\mathrm{H}_{2}$ at a pressure of $6 \mu \mathrm{bar}$ and a flow rate of $50 \mathrm{sccm}$. At the wires, molecular hydrogen $\left(\mathrm{H}_{2}\right)$ is dissociated into atomic hydrogen $(\mathrm{H})$. We varied the treatment time, ranging from $0 \mathrm{~s}$ (no hydrogen treatment) to $30 \mathrm{~s}$.

We have carefully chosen our process conditions such that the atomic hydrogen flow reaching the substrates is low enough to suppress any significant etching of the c-Si surface. Authors from JAIST in Japan have extensively reported on the influence of several process parameters, such as pressure, filament temperature, and substrate temperature on the atomic H-flux and c-Si etching rate [8-12]. For a filament temperature of $1927^{\circ} \mathrm{C}$, a process pressure of $56 \mu \mathrm{bar}$ and a distance of $10 \mathrm{~cm}$ from the filament, they found a H-atom density of $1.5 \times 10^{14} \mathrm{~cm}^{-3}$ [12]. In our experiment, we have worked at an only slightly higher filament temperature $\left(1980^{\circ} \mathrm{C}\right)$, a process pressure ( $6 \mu \mathrm{bar}$ ) that was an order of magnitude lower, and the substrate was

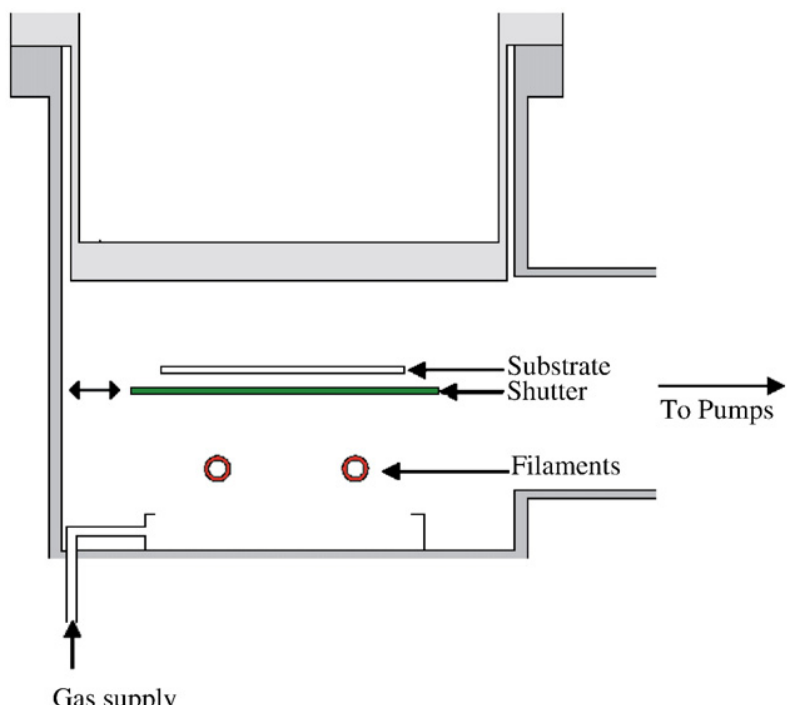

Fig. 1. Schematic overview of hot-wire CVD reactor used for the hydrogen treatment. at a filament-substrate distance of $20 \mathrm{~cm}$, which is twice the distance reported in [12]. Comparing our results to their data, and considering the very low pressure and the larger filament-substrate distance in our experiments, we conclude that the $\mathrm{H}$-flux at our substrate surface is at least one order of magnitude lower, which should lead to a suppressed c-Si etching rate [8-12]. Furthermore, our substrate temperature was sufficiently high $\left(>100{ }^{\circ} \mathrm{C}\right)$ to maintain low etching rates $[9,11]$.

Subsequently, the a-Si:H layers were deposited by PECVD at $13.56 \mathrm{MHz}$ in another chamber in the same multichamber system, without breaking the vacuum. These layers were deposited at a substrate temperature of $120^{\circ} \mathrm{C}$ from pure $\mathrm{SiH}_{4}$. The layers had a thickness of approximately $25 \mathrm{~nm}$. After hydrogen treatment and a-Si:H deposition on one side, this process was repeated on the other side after flipping the wafer in air. Directly after fabrication, the passivation samples were annealed for $16 \mathrm{~h}$ at $200{ }^{\circ} \mathrm{C}$ in $\mathrm{N}_{2}$ ambient. This annealing step is crucial to obtain high effective minority carrier lifetimes, since it enables the movement of hydrogen in the a-Si:H film towards the a-Si: $\mathrm{H} / \mathrm{c}$-Si interface, which strongly increases the passivation of dangling bonds at the interface. Such an anneal step is particularly necessary if the a-Si:H films are deposited at low $\left(\mathrm{T}<130^{\circ} \mathrm{C}\right)$ substrate temperatures $[13,14]$. The lifetime of minority carriers after application of the a-Si:H film is typically in the order of several tenths of microseconds in the as deposited state. Prolonged annealing can lead to an increase in effective lifetime of about two orders of magnitude $[13,14]$. The passivation quality of the obtained structures was assessed by means of the quasi steady state photoconductance (QSSPC) method [15], using the quasitransient mode and the generalized mode [16].

\section{Results and discussion}

In Fig. 2, the injection level dependent average minority carrier lifetimes for the fabricated passivation stacks with different atomic hydrogen pretreatment times are shown. In Fig. 3, the minority carrier lifetimes at an injection level of $10^{15} \mathrm{~cm}^{-3}$ are shown for these samples. As can be seen from Figs. 2 and 3, the effective lifetime decreases with increasing atomic hydrogen pretreatment time. The untreated reference shows the highest effective lifetime, which implies that the hot-wire hydrogen pretreatment has a detrimental effect on the passivation quality of the fabricated samples. The same trends can be observed in Fig. 4, in which the implied $V_{O C}$ is plotted versus the atomic hydrogen pretreatment time. Possible mechanisms are a change in surface roughness and increased stress and defect densities in the c-Si wafer. We have evaluated the surface roughness of the different samples by atomic force microscopy (AFM). These AFM measurements, however, show no difference in surface roughness and morphology. The rms roughness of the c-Si surfaces is below

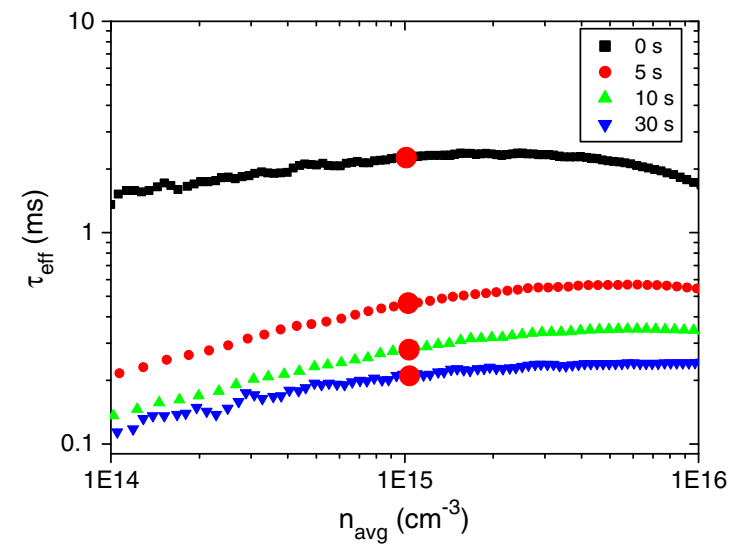

Fig. 2. Injection level dependent minority carrier lifetime for different hydrogen pretreatment times. 


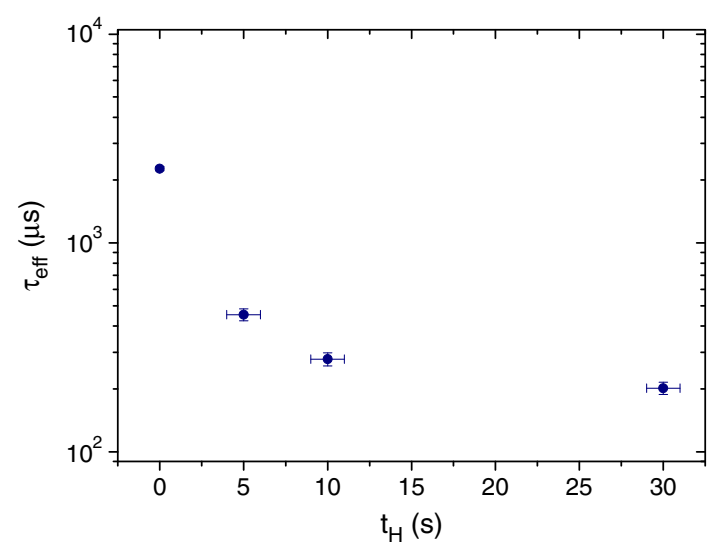

Fig. 3. Minority carrier effective lifetime at an injection level of $10^{15} \mathrm{~cm}^{-3}$ for different hydrogen pretreatment times.

the detection limit $(<1 \mathrm{~nm})$ of the used AFM setup for all samples. We speculate that an increased defect density on the c-Si surface is the most probable mechanism that causes the decrease in passivation quality of the reported samples.

Comparing our results to other groups [2-7], our results are in accordance with the results described by NREL [2,5] and Muñoz [6]. They both observe a detrimental effect of a hot-wire atomic hydrogen treatment prior to a-Si:H on cell performance and passivation quality of symmetrical layer stacks consisting of a-Si:H onto c-Si, respectively. Comparing our results with the results obtained by Conrad [3] is difficult since the hydrogen treatment was done by PECVD on (111) oriented c-Si wafers without depositing an intentional a-Si:H layer between the c-Si wafer and the oppositely doped $\mu \mathrm{c}-\mathrm{Si}: \mathrm{H}$ emitter layer. Comparing our results with Ohdaira [7], we observe the same trend for similar wire temperatures. Ohdaira, however, reports on a drastic morphological change of the c-Si for wire temperatures exceeding $1700{ }^{\circ} \mathrm{C}$, which we do not observe. For lower wire temperatures, however, Ohdaira et al. report on an improved surface passivation.

Koyama et al. $[17,18]$ have reported on surface passivation by layer stacks consisting of intrinsic a-Si:H and $\mathrm{a}_{\mathrm{SiN}} \mathrm{x}: \mathrm{H}$ deposited by HWCVD, leading to higher effective minority carrier lifetimes than for a-Si:H layers only. They ascribe this phenomenon to the fact that a- $\mathrm{SiN}_{\mathrm{x}}: \mathrm{H}$ films might significantly passivate the a-Si:H surface. Furthermore, the relatively high potential barrier for minority charge carriers of $\mathrm{a}-\mathrm{SiN}_{\mathrm{x}}: \mathrm{H}$ compared to a-Si:H should also help in reducing the surface recombination velocity and thereby increasing the effective minority carrier lifetime. The influence of the improved surface passivation by the additional deposition of an $\mathrm{a}-\mathrm{SiN}_{\mathrm{x}}$ :H layer might be different for different

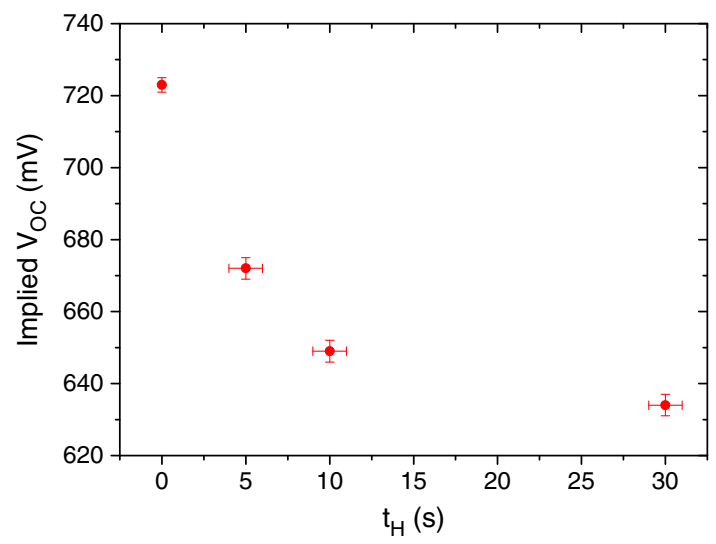

Fig. 4. Implied $\mathrm{V}_{\mathrm{OC}}$ at 1 sun illumination for different hydrogen pretreatment times.
a-Si:H layers and atomic hydrogen pretreatments. In this work, however, we have specifically studied the effect of an atomic hydrogen pretreatment on the type of a-Si:H layer showing the best passivation for c-Si surfaces in our lab.

Contrary to previous work [2-7], however, to avoid any influence on the passivation quality by chemical transfer, we have performed our hydrogen pretreatments in a new 'virgin' chamber in which no Si containing depositions have ever taken place before. In this way our experiments can unambiguously determine the role of the atomic hydrogen itself to which the wafers are exposed in this experiment.

\section{Conclusions}

From the results shown in Figs. 2-4 we conclude that the HWCVD atomic hydrogen pretreatment as described in this paper has a detrimental effect on the passivation quality of a-Si:H layers onto n-type FZ c-Si wafers. In the present experiments, the atomic $\mathrm{H}$ pretreatment by HWCVD and a-Si:H deposition by PECVD were performed in separate reactors of the same multichamber system. The hydrogen treatments have been performed in a new and clean chamber, therefore the role of redeposited a-Si:H from the chamber walls can be excluded. The role of redeposited a-Si:H can especially be very crucial if no thin intentional intrinsic a-Si:H layer is used between the c-Si wafer and the oppositely doped a-Si:H emitter layer. AFM measurements on the fabricated samples show no change in surface roughness on these samples for different treatment times. We speculate that the main mechanism that causes the decrease in passivation quality by the atomic hydrogen pretreatment is the creation of additional defects on the c-Si surface. Our work also has implications for passivation of $\mathrm{c}-\mathrm{Si}$ surfaces by a-Si:H deposited by HWCVD or PECVD in that the exposure to a reactive $\mathrm{H}$ ambient prior to deposition must be kept as short as possible under the reported conditions.

\section{Acknowledgements}

The authors would like to thank the European Commission for financial support (EU FP7 "Heterojunction Solar Cells based on a-Si c-Si" (HETSI), grant agreement no. 211821) and Dr. Monica Brinza for her help with the AFM measurements.

\section{References}

[1] M. Tanaka, M. Taguchi, T. Matsuyama, T. Sawada, S. Tsuda, S. Nakano, H. Hanafusa Y. Kuwano, Jpn. J. Appl. Phys. 31 (1992) 3518.

[2] T.H. Wang, E. Iwaniczko, M.R. Page, O. Wang, D.H. Levi, Y. Yan, Y. Xu, H.M. Branz, Mater. Res. Soc. Symp. Proc. 862 (2005) A23.5.1.

[3] E. Conrad, L. Korte, K.v. Maydell, H. Angermann, C. Schubert, R. Stangl, M. Schmidt Proc. of EU PVSEC21, Dresden, Germany, 2006.

[4] M.W.M. van Cleef, PhD Thesis, Utrecht University (1998).

[5] T.H. Wang, E. Iwaniczko, M.R. Page, D.H. Levi, Y. Yan, H.M. Branz, Q. Wang, Thin Solid Films 501 (2006) 284.

[6] D. Muñoz, C. Voz, I. Martin, A Orpella, J. Puigdollers, R. Alcubilla, F Villar, J. Bertomeu, J. Andreu, J. Damon-Lacoste, P. Roca i Cabarrocas, Thin Solid Films 516 (2008) 761.

[7] K. Ohdaira, M. Miyamoto, K. Koyama, H. Matsumura, Proc. of IEEE PVSC35, Honolulu, HI USA, 2010.

[8] A. Izumi, H. Sato, S. Hashioka, M. Kudo, H. Matsumura, Microelectron. Eng. 51-52 (2000) 495.

[9] H. Matsumura, K. Kamesaki, A. Masuda, A. Izumi, Jpn. J. Appl. Phys. 40 (2001) L289.

[10] K. Uchida, A. Izumi, H. Matsumura, Thin Solid Films 395 (2001) 75.

[11] A. Masuda, K. Kamesaki, A. Izumi, H. Matsumra, Mater. Res. Soc. Symp. Proc. 664 (2001) A4.5.1.

[12] H. Umemoto, K. Ohara, D. Morita, Y. Nozaki, A. Masuda, H. Matsumura, J. Appl Phys. 91 (2002) 1650.

[13] S. De Wolf, S. Olibet, C. Ballif, Appl. Phys. Lett. 93 (2008) 032101.

[14] J.W.A. Schüttauf, C.H.M. van der Werf, C.O. van Bommel, M.J. Huijzer, W.G.J.H.M van Sark, J.K. Rath, R.E.I. Schropp, Proc. of EU PVSEC25, Valencia, Spain, 2010.

[15] R.A. Sinton, A. Cuevas, Appl. Phys. Lett. 69 (1996) 2510

[16] H. Nagel, C. Berge, A.G. Aberle, J. Appl. Phys. 91 (1999) 6218.

[17] K. Koyama, K. Ohdaira, H. Matsumura, Appl. Phys. Lett. 91 (2010) 082108.

[18] K. Koyama, K. Ohdaira, H. Matsumura, Proc. of EU PVSEC25, Valencia, Spain, 2010 